\title{
CARACTERIZAÇÃo GEOQUÍMICA E TECTÔNICA DO MAGMATISMO PRÉ-COLISIONAL TIPO CORDILHEIRANO DE IDADE NEOPROTEROZÓICA NO CINTURÃO PARAÍBA DO SUL, ESTADO DO RIO DE JANEIRO
}

\author{
R.Machado', M.Demange ${ }^{2}$
}

\begin{abstract}
A granitogênese Neoproterozóica do cinturão Paraíba do Sul no Estado do Rio de Janeiro tem sido dividida em três grupos tectônicos principais de granitos, referidos, dos mais antigos para os mais novos, como: sin-F2, sin-F3 e sin-F4 (Machado et al., 1989; Machado \& Demange, 1992). Os granitos sin-F2, com idade mínima ao redor de $620 \mathrm{Ma}$, são divididos em dois subgrupos: um, predominante, caracterizado por granitos do tipo-I, que será discutido neste trabalho e, outro, subordinado, caracterizado como granitos tipo-S. Os granitos sin-F3, com idades entre 530 e $570 \mathrm{Ma}$, possuem composição não expandida (com predomínio de monzogranitos) e ocorrem intimamente associados a zonas de cisalhamento dúcteis de alto ângulo, tipo Além-Paraiba. Os granitos sin-F4, com idade ao redor de $500 \mathrm{Ma}$, correspondem a maciços menores, em geral na forma de stocks, de colocação mais rasa, com predomínio de composição sienogranítica a álcali-feldspato granítica. $\mathbf{O}$ controle de colocação destes maciços, ao contrário dos anteriores, parece ser independente das estruturas regionais NE-SW do Cinturão Paraiba do Sul (Machado \& Demange, 1994a, b).

Os granitos do tipo-I Cordilheirano, no cinturão Paraíba do Sul no Estado do Rio de Janeiro, são caracterizados por grandes batólitos lineares, sendo o batólito Serra dos Órgãos, o mais expressivo de todos, com extensão de $165 \mathrm{~km}$. Estes maciços, definidos como sinF2, são foliados, concordantes com a estruturação regional, de composição expandida (tonalito/granodiorito/granito), tendo sido colocados em condições metamórficas entre as fácies anfibolito a granulito (Machado et al., 1989; Machado \& Demange, 1994a, b). Entres eles, relacionam-se os batólitos Serra dos Órgãos, Angelim, Bela Joana, Serra das Abóboras, Niterói (parte) e, possivelmente, as associações charnockíticas da Ilha Grande, Illha da Marambaia e Ilha da Madeira.
\end{abstract}

Do ponto de vista geoquimico, são aqui caracterizados, os maciços Serra dos Órgãos (SO), Niterói (NI), Serra das Abóboras (SA), Angelim (AG) e Bela Joana (BJ). Os dois últimos já foram discutidos por Rêgo (1989) e Rêgo \& Figueiredo (1991, 1994), e o primeiro, por Machado \& Demange (1994a, b).

Estes maciços, de composição expandida (tonalítica/granodiorítica/granítica), são dominantemente metaluminosos, com presença de anfibólio na mineralogia principal, correspondendo a granitos cálcicos (BJ, NI) e cálcio-alcalinos (SO, AG, SA) no diagrama de Peacock. Os diferentes diagramas utilizados apontam para séries do tipo cálcio-alcalina, com os maciços SO, AG e NI sendo muito enriquecidos em ferro, mostrando no diagrama AFM um trend de evolução no limite do campo toleítico. Em diagramas de Harker mostram boa

\footnotetext{
${ }^{1}$ DGG, Instituto de Geociências, Universidade de São Paulo.

${ }^{2}$ Ecole des Mines, 35 rue Saint-Honoré, 77305 Fointainebleau, France.
} 
correlação linear do elementos, com decréscimo sistemático durante a diferenciação em $\mathrm{Fe}_{2} \mathrm{O}_{3}$, $\mathrm{MgO}, \mathrm{CaO}, \mathrm{MnO}, \mathrm{TiO}_{2}, \mathrm{Ba}, \mathrm{Zn}, \mathrm{Zr}, \mathrm{Hf}, \mathrm{Y}$, e aumento em $\mathrm{K}_{2} \mathrm{O}, \mathrm{Rb}$ e $\mathrm{Pb}$ (Machado \& Demange, 1992).

No diagrama de discriminação de ambiente tectônico de Pearce et al. (1984), a maioria das amostras destes maciços situa-se no campo dos granitos de arco vulcânico e sincolisionais, com um menor número delas distribuindo-se entre os granitos intra-placa e de cadeia oceânica. As amostras dos maciços AG e BJ restringem-se aos dois primeiros campos. No diagrama de Batchelor \& Bowden (1985), as amostras dos maciços estudados situam-se entre os campos dos fracionados mantélicos e dos granitos pré-colisionais, com algumas delas situando-se no campo sin-colisional.

Os padrões dos elementos terras raras destes maciços são semelhantes, mostrando enriquecimento em terras raras leves e empobrecimento nas pesadas, com anomalias negativas de Eu bem definidas.

Os dados aqui discutidos apontam para um magmatismo de composição expandida, comparável ao magmatismo tipo-I Cordilheirano das cadeias andina e do oeste americano. Trata-se de um magmatismo de natureza cálcio-alcalina, com características geoquímicas nitidamente pré-colisionais, de ambiente compressional, relacionado a uma margem continental ativa com subducção de litosfera oceânica. $\mathbf{O}$ zoneamento geoquímico deste magmatismo é compativel com uma zona de subducção mergulhando para NW. Os dados geocronológicos disponíveis sobre este magmatismo apontam idades ao redor de $620 \mathrm{Ma}$ (Machado et al., 1996). Estas idades, interpretadas pelos autores como idades mínimas para o magmatismo pré-colisional do Cinturão Paraíba do Sul no Estado do Rio de Janeiro, mostram uma diferença de 30 a $40 \mathrm{Ma}$ em relação aos valores considerados por Figueiredo \& Campos Neto (1993); Campos Neto \& Figueiredo (1995) e Wiedemann (1993) para a definição de um arco magmático brasiliano na região, o "arco magmático Rio Doce" dos primeiros autores.

\section{Referências Bibliográficas}

BATCHELOR, R.A.; BOWDEN, P. (1985) Petrogenetic interpretation of granitoid rock series using multicationic parameters. Chemical Geology, v.48, n.1-4, p.43-55.

CAMPOS NETO, M.C.; FIGUEIREDO, M.C.H. (1995) The Rio Doce orogeny, southestern Brazil. Journal of South American Earth Sciences, v.8, n.2, p.143-162.

FIGUEIREDO, M.C.H.; CAMPOS NETO, M.C. (1993) Geochemistry of the Rio Doce magmatic arc, southeastern Brazil. Anais da Academia Brasileira de Ciências. Suplemento, v. 65 , n.1, p.63-81.

MACHADO, R.; DEMANGE, M. (1992) Granitogênese brasiliana no estado do Rio de Janeiro: caracterização geoquímica, modelo tectônico e considerações geológicas sobre o embasamento e a cobertura do cinturão Ribeira na região. In: CONGRESSO BRASILEIRO DE GEOLOGIA, 37., São Paulo, 1992. Boletim de Resumos Expandidos-Simpósios. São Paulo, SBG-SP, v.1, p.379-380.

MACHADO, R.; DEMANGE, M. (1994a) O batolito cordilherano Serra dos Órgãos: um exemplo de arco magmático brasiliano com assinatura tolética no sistema de cisalhamento Paraiba do Sul, no estado do Rio de Janeiro. In: CONGRESSO BRASILEIRO DE GEOLOGIA, 38., Camboriú, 1994. Boletim de Resumos Expandidos-Simpósios. Camboriú, SBG/DNPM/CPRM, v.1, p.114-115.

MACHADO, R.; DEMANGE, M. (1994b) Classificação estrutural e tectônica dos granitóides neoproterozóicos do cinturão Paraíba do Sul no estado do Rio de Janeiro. Boletim IGUSP.Série Científica, v.25, p.81-96. 
MACHADO, R.; DEMANGE, M.; VIALETTE, Y. (1996) Idades geocronológicas Rb-Sr da granitogênese brasiliana no segmento setentrional da faixa Ribeira, estado do Rio de Janeiro. In: CONGRESSO BRASILEIRO DE GEOLOGIA, 39., Salvador, 1996. Anais. Salvador, SBG-BA, v.1, p.38-40.

MACHADO, R.; DEMANGE, M.; MONTEIRO, R.L. (1989) Granitóides do estado do Rio de Janeiro: nivel estrutural de colocação e suas relações com as fases de deformação e com o grau de metamorfismo. In: SIMPÓSIO DE GEOLOGIA DE SUDESTE, 1., São Paulo, 1989. Boletim de Resumos. São Paulo, SBG-RJ/SP, p.145-146.

PEARCE, J.A.; HARRIS, N.B.W.; TINDLE, A.G. (1984) Trace element discrimination diagrams for the tectonic interpretation of granitic rocks. Journal of Petrology, v.25, n.4, p.956-983.

REGO, I.T.S.F. (1989) Petrologia e geoquímica da unidade charnockítica Bela Joana, região de São Fidelis-RJ. São Paulo, 348p. (Tese - Doutorado) - Instituto de Geociências, Universidade de São Paulo. 